\title{
A HIPERVULNERABILIDADE DO CONSUMIDOR CRIANÇA FRENTE À PUBLICIDADE INFANTIL
}

\author{
Jovana De Cezaro ${ }^{1}$ \\ Rogerio da Silva ${ }^{2}$
}

RESUMO: O presente artigo visa analisar a vulnerabilidade do consumidor criança frente à publicidade infantil. Objetiva-se debater se a legislação existente, Constituição Federal, Código de Defesa do Consumidor, entre outros, são suficientes para evitar práticas abusivas e enganosas, resguardando os direitos dos consumidores crianças. Esses integram o grupo dos denominados hipervulneráveis, pois possuem a vulnerabilidade agravada em função de sua condição especial de criança. Na sociedade de consumo, abre-se espaço para o surgimento de publicidade enganosa e abusiva voltada ao público infantil, com a finalidade de estimular desejos e incentivar o consumo.

PALAVRAS-CHAVE: Consumidor. Hipervulnerabilidade. Infantil. Publicidade. Vulnerabilidade.

\section{CHILD CONSUMER HYPERVULNERABILITY IN FRONT OF CHILD ADVERTISING}

ABSTRACT: This article aims to analyze the vulnerability of the child consumer to child advertising aimed at this audience. The objective is to debate whether the existing legislation, Federal Constitution, Consumer Protection Code, among others, are sufficient to avoid abusive and deceptive practices, safeguarding the rights of children consumers. These consumers are part of the group of so-called hypervulnerables, as they have increased vulnerability due to their special condition as a child. In the consumer society, there is room for the appearance of misleading and abusive advertising aimed at children, with the purpose of instigating consumption and keeping the economy active.

KEYWORDS: Consumer. Hypervulnerability. Children. Publicity. Vulnerability.

\section{INTRODUÇÃO}

Nas sociedades contemporâneas, as crianças desempenham um papel relevante na economia e influenciam no consumo das famílias. Em decorrência das necessidades os pais precisam passar longos períodos fora de casa e consequentemente não conseguem

\footnotetext{
${ }^{1}$ Mestranda do Programa de Pós Graduação em Direito da Universidade de Passo Fundo - UPF. Pós-Graduanda em Direito do Trabalho. Graduada em Ciências Jurídicas e Sociais pela Universidade de Passo Fundo - UPF. Advogada. Endereço postal: Rua Dr. Parobé, número 551, Centro, Casca/RS. CEP: 99260-000. Endereço eletrônico: jovanadc@hotmail.com.

${ }^{2}$ Vice-Reitor da Universidade de Passo Fundo - UPF. Especialista em Contratos e Responsabilidade Civil UPF. Mestre e Doutor em Direito pela Universidade de Santa Cruz do Sul - UNISC. Endereço postal: Rua Alferes Rodrigues, número 385, apartamento 702, Bairro Boqueirão, Passo Fundo/RS. CEP: 99025-070. Endereço eletrônico: rogerio@upf.br.
} 
acompanhar todas as atividades dos filhos que acabam sendo atraídos pela televisão e a internet.

As crianças são bombardeadas diariamente com anúncios inapropriados, sempre com o intuito de estimular desejos e aumentar os lucros das companhias. Por estarem em período de formação, são facilmente seduzidas por publicidades que utilizam práticas abusivas ou enganosas contrariando a legislação vigente.

A fim de conquistar o consumidor, a publicidade apela para o desejo e a fantasia das pessoas, despertando um sentimento de necessidade. $\mathrm{O}$ presente artigo analisa os cuidados redobrados com a publicidade voltada ao público infantil, denominados de hipervulneráveis e que são facilmente influenciados ao consumo, porta de entrada do consumismo.

Tendo-se como base a Constituição Federal do Brasil de 1988, o Estatuto da Criança e do Adolescente, o Código de Defesa do Consumidor, entre outros, busca-se verificar se estas legislações são suficientes para proteger os consumidores crianças da pratica de publicidade abusiva ou enganosa.

\section{DA SOCIEDADE DE CONSUMO: DO HIPERCONSUMO AO CONSUMOCENTRISMO}

Nas últimas décadas o consumo foi fortemente acelerado em função da economia globalizada e do acesso à internet. Ambas, romperam definitivamente as fronteiras e facilitaram o acesso a produtos e serviços. Para autores como Lipovetsky, já estamos na era do hiperconsumismo onde se consome mais do que o necessário.

O consumo é essencial para a sobrevivência humana e possui "raízes tão antigas quanto os seres vivos" (BAUMAN, 2008, p. 37). Já a sociedade de consumo tem como marco inicial o ano de 1920, porém, somente nos anos de 1950-1960 o conceito se expandiu (LIPOVETSKY, 2007, p. 23).

Lipovetsky divide o surgimento da sociedade de consumo em três momentos principais, denominados por ele de ciclos. O primeiro se inicia por volta do ano de 1880 e termina com a Segunda Guerra Mundial, por volta de 1945. Nesse se dá a expansão da produção em massa, principalmente, pela reestruturação das fábricas, tentativa de democratização do acesso aos bens e pelo baixo preço de venda das mercadorias. $\mathrm{O}$ autor 
afirma que nesse momento criou-se "um consumo de massa inacabado, com predominância burguesa" (2007, p. 26-29).

Nessa primeira fase também desenvolveu-se o marketing de massa ${ }^{3}$, a padronização dos produtos, a marca e o consumidor moderno. Conforme Lipovetsky, esse período "transformou o cliente tradicional em consumidor moderno, em consumidor de marcas a ser educado e seduzido especialmente pela publicidade" 4 . Ainda, foi responsável por criar o denominado "consumo-sedução", o qual, continua hoje, fortemente em vigor (2007, p. 30-31).

O segundo momento que inicia por volta de 1950 e se estende até 1970, se identifica com o que se chamou de "sociedade da abundância". Houve o completo aperfeiçoamento da compra de bens duráveis, elevando o consumo e modificando a sua estrutura (LIPOVETSKY, 2007, p. 32).

A segunda fase foi responsável, também, por levar o poder de compra as mais diversas camadas sociais ${ }^{5}$, além de difundir o crédito. Edifica-se a "sociedade do consumo de massa", criando, "em grande escala a vontade crônica dos bens mercantis, o vírus da compra, a paixão pelo novo, um modo de vida centrado nos valores materialistas". A fase dois se mostra como a "sociedade do desejo" (LIPOVETSKY, 2007, p. 33-36).

O terceiro e último ciclo é o que se encontra em vigência desde o ano de 1970 até a atualidade, mantendo a sociedade de consumo. Por sua vez, esse período caracteriza-se pela incessante vontade de consumir e "de uma incapacidade de eliminar os apetites do consumo, sendo toda saturação de uma necessidade acompanhada imediatamente por novas procuras" (LIPOVETSKY, 2007, p. 37-38).

O que sustenta essa sociedade de consumo é o próprio indivíduo, o qual consome constantemente. Nesse sentido, importa destacar o consumo necessário, denominado de primário e o consumo exacerbado, denominado de secundário. O primeiro é aquele que visa

\footnotetext{
${ }^{3}$ Lipovetsky aborda que "até os anos 1880, os produtos eram anônimos, vendidos a granel, e as marcas nacionais, muito pouco numerosas. A fim de controlar os fluxos de produção e de rentabilizar seus equipamentos, as novas indústrias acondicionaram elas mesmas seus produtos, fazendo publicidade em escala nacional em torno de sua marca. Pela primeira vez, empresas consagram enormes orçamentos à publicidade [...]" (2007, p. 29)

${ }^{4}$ Assim, "com a tripla invenção da marca, do acondicionamento e da publicidade, apareceu o consumidor dos tempos modernos, comprando o produto sem a intermediação obrigatória do comerciante, julgando os produtos a partir de seu nome mais que a partir de sua composição, comprando uma assinatura no lugar de uma coisa" (LIPOVETSKY, 2007, p. 30).

5 Assim, "pela primeira vez, as massas têm acesso a uma demanda material mais psicologizada e mais individualizada, a um modo de vida (bens duráveis, lazeres, férias, moda) antigamente associado às elites sociais" (LIPOVETSKY, 2007, p. 33).
} 
tão somente satisfazer as necessidades essenciais do indivíduo, seja de alimentos, abrigo e proteção (SILVA, 2014, p. 30-31).

Dahinten e Dahinten afirmam que consumir passou a representar a exata medida do que é viver dignamente, porque, por meio desse ato, afasta o "indivíduo do estado de miserabilidade" (2016, p. 08). O segundo não visa somente satisfazer as necessidades essenciais, mas sim suprir aquelas necessidades que são pensadas e imaginadas pelo consumidor (SILVA, 2014, p. 30-31).

Assim, "enquanto as necessidades reais nos garantem a sobrevivência e o conforto vital, as imagináveis costumam nos levar por caminhos tortuosos de sedução, manipulação e desejos insaciáveis". Ainda, Silva afirma que, “consumir é preciso para viver, mas viver para consumir pode ser uma das maneiras mais eficazes de transformar a vida em uma morte existencial" (2014, p. 29-31).

Quando se deixa de consumir somente o necessário e passa-se a consumir exacerbadamente, entra em cena o consumismo. Para Bauman o consumismo é:

[...] maneira distinta do consumo, que é basicamente uma característica e uma ocupação dos seres humanos como indivíduos, o consumismo é um atributo da sociedade. Para que uma sociedade adquira esse atributo, a capacidade profundamente individual de querer, desejar e almejar deve ser [...] destacada (alienada) dos indivíduos e reciclada/reificada numa força externa que coloca a sociedade de consumidores em movimento e a mantém em curso como uma forma específica de convívio humano, enquanto ao mesmo tempo estabelece parâmetros específicos para as estratégicas individuais de vida que são eficazes e manipula as probabilidades de escolha e conduta individuais (BAUMAN, 2008, p. 41).

Ainda na concepção de Bauman, "a sociedade de consumo prospera enquanto consegue tornar perpétua a não satisfação de seus membros". Para isso, faz-se valer de métodos utilizados conjuntamente: desvalorizar a mercadoria logo após a mesma ter sido inserida na consciência dos consumidores como necessidade e satisfazer todas as necessidades dos indivíduos, a fim de que os desejos e as novas vontades tenham surgimento e façam com que o esforço despendido para a satisfação de uma necessidade se torne uma compulsão (grifos do autor, 2008, p. 64).

Na mesma linha é o entendimento de Santos, para quem [...] "O consumo é o grande emoliente, produtor ou encorajador de imobilismo. Ele é, também, um veículo de narcisismos, por meio dos seus estímulos estéticos, morais, sociais; e aparece como o grande fundamentalismo do nosso tempo, porque alcança e envolve toda gente” (2015, p. 49). 
O consumismo e a sociedade de hiperconsumo podem gerar problemas individuais e coletivos, tais como: o esgotamento das matérias-primas e a crescente geração de lixo e a sua destinação, tendo em vista que o consumidor visa obter os mais recentes produtos, substituindo e descartando rapidamente os antigos, alimentando o ciclo da compra (rápida, incansável e insaciável) e descarte (irresponsável e despreocupadamente). O "pleno funcionamento do sistema produtivo depende da ampliação dos níveis de consumo que, por sua vez, pode acarretar danos socioambientais" (BRITO; COSTA, 2020, p. 3).

Na sociedade de consumo, os sujeitos passam a ser rodeados pela multiplicação dos objetos, dando origem a um novo modo de ver a espécie humana e a um novo modelo de relações sociais. Isso ocorre pois, nessa sociedade de consumo, os indivíduos deixam de ser cercados por outros indivíduos e passam a ser cercados por objetos (BAUDRILLARD, 1995, p. 15).

Com isso surge um novo forma de consumir denominado de "hiperconsumo", que criou o modelo, denominado por Lipovetsky, de "consumo-mundo". Nesse sentido, o espírito do consumo passou a se infiltrar não somente na cultura, mas também na família, na política, na religião e, principalmente, no tempo livre dos indivíduos. O hiperconsumidor ${ }^{6}$ busca no ato de consumir não somente bens materiais, mas principalmente, satisfações psicológicas e imediatas (2007, p. 14).

O hiperconsumo "passou a integrar o cotidiano das pessoas, introduzido através das novelas, filmes, revistas, e outros meios de publicidade, sempre impondo a ideologia hiperconsumista e um adestramento para o consumocentrismo na sociedade contemporânea" (CALGARO; PEREIRA, 2016, p. 74).

Entende-se que já se ultrapassou a denominada sociedade hiperconsumista, dando azo a uma sociedade consumocentrista. Nesse sentido, o consumir torna-se a ser o centro da sociedade, ou seja, o consumo se encontra no centro de todas as decisões que envolvem o indivíduo. Assim, o consumo "passa a ser o elemento principal das atividades humanas,

\footnotetext{
${ }^{6} \mathrm{O}$ hiperconsumidor é tido como um sujeito peculiar, "uma espécie de turbo-consumidor desajustado, instável e flexível, amplamente liberto das antigas culturas de classe, imprevisível em seus gostos e em suas compras. De um consumidor sujeito às coerções sociais da posição, passou-se a um hiperconsumidor à espreita de experiências emocionais e de maior bem-estar, de qualidade de vida e de saúde, de marcas e de autenticidade, de imediatismo e de comunicação. O consumo intimizado tomou o lugar do consumo honorífico, em um sistema em que o comprador é cada vez mais informado e infiel, reflexivo e 'estético'. Pouco a pouco, desvanecem-se os antigos limites de tempo e de espaço que emolduravam o universo do consumo: eis-nos em um cosmo consumista contínuo, dessincronizado e hiperindividualista, no qual mais nenhuma categoria de idade escapa às estratégias de segmentação do marketing, mas no qual cada um pode construir à la carte seu emprego do tempo, remodelar sua aparência, moldar suas maneiras de viver" (LIPOVETSKY, 2007, 14).
} 
deslocando o ser para o ter e, posteriormente, para o aparentar" (PEREIRA; CALGARO; PEREIRA, 2016, p. 267).

O pensamento e a atividade do consumidor moderno estão voltadas ao consumir, visto que, por meio desse ato, se realiza como ser individual e social, pois "ele somente é se consumir”. Ou seja, “consumir é existir” (PEREIRA; CALGARO; PEREIRA, 2016, p. 267). Nesse sentido, com o consumocentrismo,

[...] as questões sociais e ambientais são postas em segundo plano, visto que para o consumidor o importante é consumir; para as grandes corporações o importante é lucrar. Isso faz com que a natureza e as questões sociais deixem de ser observadas. Por um lado, que a natureza tenha seus recursos explorados desmedida e insustentavelmente e, por outro, que e as desigualdades sociais e a pobreza sejam tidas como algo aceitável na sociedade (PEREIRA; CALGARO; PEREIRA, 2016, p. 267).

A sociedade de consumo, pautada na busca incessante por felicidade, encontra na publicidade a promessa de satisfação de seus desejos. O consumismo "pode comprometer a capacidade do sujeito de refletir sobre si mesmo e acerca do modo como se relaciona com os outros e com os objetos de consumo" (BRITO; COSTA, 2020, p. 10). Retomando a visão de Santos "Consumismo e competitividade levam ao emagrecimento moral e intelectual da pessoa, à redução da personalidade e da visão do mundo, convidando, também, a esquecer a oposição fundamental entre a figura do consumidor e a figura do cidadão [...]” (2015. p. 49).

A sociedade de consumo pode ser compreendida então como uma estrutura montada em torno do verbo adquirir, onde o homem é motivado e impulsionado a consumir. Para despertar o desejo no consumidor de coisas e de objetos utiliza-se da publicidade, que desempenha papel de fundamental relevância.

\section{A PUBLICIDADE NO CÓDIGO DE DEFESA DO CONSUMIDOR}

$\mathrm{Na}$ sociedade de consumo a publicidade é uma ferramenta essencial, e tem como objetivo principal, despertar desejos em adquirir bens ou contratar serviços, instigando o consumo, uma vez que sua atividade comercial estimula a comunicação.

$\mathrm{Na}$ era da informação, a principal forma de interação entre fornecedor e o consumidor se dá através do marketing. O marketing é uma área ligada a geração do lucro, que possui processos para criar, comunicar, entregar e trocar ideias que venham a conquistar a atenção do público provocando a ação de compra (GRINOVER et al., 2019, p. 264). 
O marketing abrange a identificação e a satisfação das necessidades humanas e sociais. Assim, "trata-se da ciência e da arte de investigar, criar e entregar valor para satisfazer às necessidades de um mercado-alvo com lucro, identificando as necessidades e os desejos não realizados" (VELHO, 2018, p. 16).

O mesmo se utiliza de recursos como a publicidade, que busca persuadir e incentivar o consumo de bens colocados do mercado. Conforme denotam Gomes e Castro, a evolução da publicidade está associada ao "desenvolvimento da sociedade de consumo" (2008, p. 03). Todos os dias a população é bombardeada por inúmeras formas de publicidade, ela é onipresente, ou seja, está em todos os lugares, criando uma conexão direta com o consumidor.

Conforme Fradera, a publicidade faz parte do nosso cotidiano, desde a infância até os nosso últimos dias. É “através dela que o Mundo [...] nos é oferecido, como se fora uma vitrine, onde são expostas as 'novidades' que, a partir de então, passam a ser 'necessidades', mostradas que são como indispensáveis ao conforto e à atualização da vida e dos lares (1992, p. 06).

Ela "invade espaços mais amplos do nosso cotidiano, principalmente aqueles já dominados pelos meios de comunicação de massa" (GOMES; CASTRO, 2008, p. 04). Ainda,

[...] atua junto aos consumidores, motivando seu entendimento como um verdadeiro jogo em que cada um dos sujeitos envolvidos busca agir sobre o outro na tentativa de com-vencer. O importante, portanto, é priorizar não o quê, e sim o como dizer, que faz com que o consumidor não apenas atente para o que lhe é oferecido, mas se sensibilize ou manifeste claramente sua adesão (GOMES; CASTRO, 2008, p. 12, grifos do autor).

A publicidade é arte de despertar no público o desejo da compra, levando-o a ação (GONÇALES, 2009, p. 07). Em tudo o que se veste, se consome ou se utiliza está presente uma marca publicitária. Conceder propagação a um produto ou serviço é, na esfera das relações de consumo, muito mais do que tornar aquele objeto conhecido, mas causar o desejo de compra no consumidor.

[...] a publicidade funciona como uma espécie de ritual: trata-se de dar a conhecer, a um público determinado, aspectos positivos e/ou vantagens de produto(s), marca(s) ou serviço(s), com vistas a obter a aceitação desse público e a consequente aquisição do que lhe foi mostrado (GOMES; CASTRO, 2008, p. 05).

$\mathrm{Na}$ concepção de Lipovetsky, a "publicidade libertou-se da racionalidade argumentativa, pela qual se obrigava a declinar a composição dos produtos, segundo uma 
lógica utilitária" e "mergulhou num imaginário puro, livre da verossimilhança, aberto à criatividade sem entraves, longe do culto da objetividade das coisas" (2000, p. 8).

A publicidade se utiliza, dentro do sistema capitalista, de inúmeras alternativas para o consumidor adquirir no mercado, é o principal meio para esse sistema atingir seu objetivo e o mais eficaz para alcançar a visibilidade da sociedade. A preocupação do Direito Consumerista é impor limites a esses anunciantes, em virtude da crescente publicidade enganosa e abusiva.

O conceito de publicidade e propaganda ${ }^{7}$ é distinto. A primeira objetiva o lucro em si, induz o consumidor a pensar que necessita aquele bem para sua felicidade, o que não passa de uma jogada de marketings perante a sociedade atual que busca status para suprir seus anseios. Ao passo que a segunda possui um conjunto de ideias e pensamentos relacionado a arte de notificar a sociedade, comunicando fatos que o setor midiático almeja tornar conhecido (CAVALIERI FILHO, 2019, p. 152).

Assim, os termos publicidade e propaganda não significam a mesma coisa, portanto não se pode confundi-los ${ }^{8}$. O Código de Defesa do Consumidor se direciona à publicidade, pois ela tem um objetivo comercial e não à propaganda, considerando que não há a objetivação do lucro nesta (GRINOVER et al., 2019, p. 322).

Mas, para que as práticas comerciais aconteçam de maneira adequada, ocorre o controle da publicidade, o que não se confunde com a eliminação da publicidade. Controla-se a publicidade "vedando-se-lhe apenas e tão somente os abusos no exercício desse direito de realizar publicidade" (NERY JR., 2014, p. 13).

Assim, vários são os mecanismos de autorregulamentação publicitária, dentre eles o Código de Defesa do Consumidor, o Código Brasileiro de Autorregulamentação Publicitária e o Conselho Nacional de Autorregulamentação Publicitária (CONAR). Desta maneira, o Código de Defesa do Consumidor proíbe qualquer forma de publicidade ilícita, entendida como enganosa ou abusiva ${ }^{9}$.

\footnotetext{
${ }^{7}$ A propaganda é um modo específico de persuadir, visando influenciar o indivíduo sobre fins ideológicos, religiosos, políticos ou cívicos, porém sem qualquer intuito econômico. Historicamente a propaganda não almeja uma vantagem financeira, entretanto busca a difusão de ideais (CHAISE, 2001, p. 10).

${ }^{8}$ Os termos publicidade e propaganda são utilizados no cotidiano de forma incerta para denominar qualidade ampla do trabalho publicitário, essa confusão ocorre até mesmo na legislação brasileira, tendo como exemplo o artigo 60 do Código de Defesa do Consumidor que regulamentou a "contrapropaganda" quando dever-se-ia falar em "contrapublicidade" (GRINOVER et al., 2019, p. 368).

9 Artigo 37 do Código de Defesa do Consumidor: "É proibida toda publicidade enganosa ou abusiva. $\S 1^{\circ} \mathrm{E}$ enganosa qualquer modalidade de informação ou comunicação de caráter publicitário, inteira ou parcialmente falsa, ou, por qualquer outro modo, mesmo por omissão, capaz de induzir em erro o consumidor a respeito da
} 
Define-se como publicidade enganosa aquela que "viola o dever de veracidade e clareza estabelecidos pelo CDC". Já a publicidade abusiva "é aquela que viola valores ou bens jurídicos considerados relevantes socialmente (tais como meio ambiente, segurança e integridade dos consumidores)" bem como, "a que se caracteriza pelo apelo indevido a vulnerabilidade agravada de determinados consumidores, como crianças e idosos" (MIRAGEM, 2013, p. 251).

O artigo 36 do Código de Defesa do Consumidor ${ }^{10}$ aborda que a publicidade deve ser clara e fácil, de modo que o consumidor identifique-a no momento da exposição, não pode enganar o consumidor. Ainda, conforme normas do Código Brasileiro de Autorregulação Publicitária, a atividade publicitária deve ser ostensiva ${ }^{11}$ e o anúncio tem que ser distinguido como tal $^{12}$, a fim de evitar prováveis abusos por parte dos fornecedores e com o intuito de proteger a parte mais frágil da relação de consumo.

Também, como forma de proteção ao consumidor, tem-se o Conselho Nacional de Autorregulamentação Publicitária (CONAR), com a missão de "impedir que a publicidade enganosa ou abusiva cause constrangimento ao consumidor ou a empresas, e defender a liberdade de expressão comercial", ou seja, zela pelos interesses dos profissionais e dos consumidores simultaneamente.

O controle legal leva em conta que, uma publicidade mal elaborada acarreta prejuízos ao destinatário, tendo em vista que este é a parte mais vulnerável dessa relação e terá prejudicado seu direito de escolher pela compra de um produto ou na contratação de um serviço, seja porque as informações repassadas relativa a esse bem foram equivocadas, seja porque coloca em risco à saúde, à segurança e o bem estar ou, ainda, pelo fato de omitir as informações propositalmente, impossibilitando o conhecimento prévio do consumidor acerca

natureza, características, qualidade, quantidade, propriedades, origem, preço e quaisquer outros dados sobre produtos e serviços. $\S 2^{\circ}$ É abusiva, dentre outras a publicidade discriminatória de qualquer natureza, a que incite à violência, explore o medo ou a superstição, se aproveite da deficiência de julgamento e experiência da criança, desrespeita valores ambientais, ou que seja capaz de induzir o consumidor a se comportar de forma prejudicial ou perigosa à sua saúde ou segurança".

${ }^{10}$ Artigo 36 do Código de Defesa do Consumidor: "A publicidade deve ser veiculada de tal forma que o consumidor, fácil e imediatamente, a identifique como tal. Parágrafo único. O fornecedor, na publicidade de seus produtos ou serviços, manterá, em seu poder, para informação dos legítimos interessados, os dados fáticos, técnicos e científicos que dão sustentação à mensagem".

${ }^{11}$ Artigo $9^{\circ}$ do Código Brasileiro de Autorregulamentação Publicitária: "A atividade publicitária de que trata este Código será sempre ostensiva, com indicação clara da marca, da firma ou da entidade patrocinadora de qualquer anúncio ou campanha".

12 Artigo 28 do Código Brasileiro de Autorregulamentação Publicitária: "O anúncio deve ser claramente distinguido como tal, seja qual for a sua forma ou seu meio de veiculação”. 
das peculiaridades negativas da mercadoria adquirida. O consumidor não pode se sentir lesado em face do conteúdo da oferta.

\section{A HIPERVULNERABILIDADE DO CONSUMIDOR CRIANÇA: PROTEÇÃO}

\section{LEGAL}

O Direito do Consumidor visa tutelar um grupo específico de indivíduos nas relações de consumo, quais sejam os consumidores. A vulnerabilidade é condição intrínseca de todo e qualquer consumidor, pois estes são a parte mais frágil na relação de consumo. Contudo, determinada categoria de consumidores merecem maior atenção, são os considerados hipervulneráveis.

Define-se consumidor como "toda pessoa física ou jurídica que adquire ou utiliza produto ou serviço como destinatário final” (BRASIL, 1990). A lei equipara a consumidor à "coletividade de pessoas, ainda que indetermináveis, que haja intervindo nas relações de consumo". O conceito de vulnerabilidade, de acordo com Moraes e

[...] sob o enfoque jurídico, é então, o princípio pelo qual o sistema jurídico positivado brasileiro reconhece a qualidade ou condição daquele(s) sujeito(s) mais fraco(s) na relação de consumo, tendo em vista a possibilidade de que venha(m) a ser ofendido(s) ou ferido(s), na sua incolumidade física ou psíquica, bem como no âmbito econômico, por parte $\operatorname{do}(\mathrm{s})$ sujeito(s) mais potente(s) da mesma relação (2009, p. 125).

Importante mencionar a existência de diversas espécies de vulnerabilidade ${ }^{13}$. Para fins desse estudo, destaca-se a vulnerabilidade agravada do consumidor infantil, também chamada de hipervulnerabilidade. Esses consumidores possuem fragilidades maiores e necessitam de mais cuidados e proteção, pois podem ser vítimas fáceis, tendo em vista sua falta de maturidade física e mental, ou seja, são pessoas em desenvolvimento ${ }^{14}$.

A hipervulnerabilidade é uma situação de agravamento da vulnerabilidade do consumidor. O prefixo hiper deriva do "termo grego hypér e serve para designar um alto grau,

\footnotetext{
${ }^{13}$ Destaca-se a vulnerabilidade fática ou socioeconômica, a vulnerabilidade técnica, a vulnerabilidade jurídica ou científica, a vulnerabilidade informacional. Ainda, importante citar a vulnerabilidade política ou legislativa, a vulnerabilidade psíquica ou biológica, a vulnerabilidade ambiental, entre outras.

14 A vulnerabilidade da criança é reconhecida universalmente pela Declaração dos Direitos da Criança, Proclamada pela Resolução da Assembleia Geral das Nações Unidas n. ${ }^{\circ} 1386$ (XIV), de 20 de Novembro de 1959, a qual afirma que "a criança, por motivo da sua falta de maturidade física e intelectual, tem necessidade uma protecção e cuidados especiais, nomeadamente de protecção jurídica adequada, tanto antes como depois do nascimento".
} 
ou aquilo que excede a medida normal". Uma vez "acrescentada este à palavra vulnerabilidade, obtém-se uma situação de intensa fragilidade, que supera os limites do que seria uma situação de fraqueza" (SCHMITT, 2014, p. 217-218).

Benjamin passou a utilizar o termo hipervulneráveis em suas decisões, ao passo que aborda que "ao Estado Social importam não apenas os vulneráveis, mas sobretudo os hipervulneráveis, pois são esses que, exatamente por serem minoritários e amiúde discriminados ou ignorados, mais sofrem com a massificação do consumo [...]" (2020, p. 3).

Ainda, os hipervulneráveis são definidos como "consumidores ignorantes e de pouco conhecimento, de idade pequena ou avançada, de saúde frágil, bem como aqueles cuja posição social não lhes permite avaliar com adequação o produto ou serviço que estão adquirindo" (GRINOVER et al., 2019, p. 381).

O público infantil ${ }^{15}$, considerados hipervulneráveis, constitui mundialmente um mercado rentável e por esse motivo, cada dia mais, as crianças estão expostas as mensagens publicitárias. Com o crescimento da internet, milhares de produtos são dirigidos a esse público, repletos de apelos comerciais, o que os transforma em vorazes consumidores.

Destaca Magalhães, em seu voto no Recurso Especial número 1.558.086 - SP, na Segunda Turma do Superior Tribunal de Justiça, que as crianças tem seu discernimento incompleto, mas, por outro lado é uma influenciadora do adulto no ato de compra, "tem uma enorme capacidade de convencimento sobre os seus pais, responsáveis ou familiares, voltada à aquisição daqueles produtos que lhe interessam" (2016, p. 9). É comum encontrar crianças opinando, ou até mesmo implorando para seus pais comprarem determinado produto, o que significa que a publicidade infantil vem atingindo seu objetivo, ou seja, instigar a venda.

Como princípio norteador e como forma de proteger a vulnerabilidade do consumidor destaca-se o princípio da identificação, o qual discorre que toda publicidade deve ser identificada, permitindo que o consumidor saiba que está sendo alvo da oferta de um produto ou serviço. Segundo Cavalieri Filho "a publicidade só é lícita quando o consumidor puder identificá-la imediata e facilmente" (2019, p. 152).

Para se manter atrativa e atingir seus objetivos, a publicidade deve sempre reinventar-se. Assim, são utilizadas algumas técnicas de persuasão como meio de aprisionamento do sujeito, incutindo no mesmo falsas necessidades de consumo. A técnica

\footnotetext{
${ }^{15}$ Segundo o Estatuto da Criança e do Adolescente considera-se criança a pessoa de até 12 anos de idade incompletos e adolescente aquela entre doze e dezoito anos de idade.
} 
mais utilizada é merchandising ${ }^{16}$ que também é conhecido como "vendedor silencioso", porque "não confessa o fim publicitário da mensagem" (LOPES, 2011, p. 04).

Visando alcançar o público infantil, as ações de publicidade se utilizam dos Youtubers, conhecidos como influenciadores digitais, e também de técnicas como o unboxing, o advergaming, o advergame, entre outras. O unboxing, palavra de origem inglesa, é o nome atribuído a vídeos onde pessoas desembrulham produtos narrando os seus mínimos detalhes (TEIXEIRA, 2018, p. 472).

Os unboxing são conteúdos produzidos e lançado nas redes sociais digitais por influenciadores que "registram o momento da abertura de embalagens de produtos", ou seja, "trata-se da gravação em vídeo da ação de desempacotamento do bem por parte do comprador, que mostra e narra o processo, sempre de forma pessoal" (SATO, 2016, documento não paginado).

O advergaming divide-se em duas modalidades. A primeira "é a inserção de logomarcas e produtos no cenário de jogos eletrônicos" com o intuito de promover, de modo interativo e dinâmico, determinada marca, empresa, produto ou ideia (BURROWES, 2005, p. 215). A segunda, denominada advergame, é composta por jogos criados especificamente para divulgar uma marca e vender um produto (FERNANDES et al., 2014, p. 93).

Por ser o público infantil, consumidores hipervulneráveis, parcela bastante lucrativa no mercado global, é assegurado aos mesmos proteção contra a publicidade enganosa ou abusiva, constituindo-se como direito do consumidor mirim. A publicidade infantil tem como finalidade fomentar uma lógica consumista que se fundamenta no comprar e descartar.

Embora a Constituição Federal de 1988 tenha conferido uma proteção à liberdade de fazer publicidade, ela não é ilimitada. A Carta Maior prevê restrições a veiculação publicitária em seus parágrafos $3^{\circ}$ e $4^{\circ}$ do artigo 220 . O parágrafo $3^{017}$ prescreve que compete à lei federal estabelecer novas restrições à publicidade de produtos ou serviços que possam ser nocivos à

\footnotetext{
${ }^{16} \mathrm{O}$ merchandising "é a inserção proposital de produtos ou serviços nos programas de televisão, como novelas e programas de auditório, ou filmes, no enredo destas histórias na sua real situação de consumo. Esta colocação advém de um contrato entre fornecedor e a contraprestação pelo espaço oferecido para a divulgação do seu produto" (BOLKENHAGEN, 2011, p. 06).

17 Artigo 220 da Constituição Federal de 1988: “[...] § $3^{\circ}$ Compete à lei federal: I - regular as diversões e espetáculos públicos, cabendo ao Poder Público informar sobre a natureza deles, as faixas etárias a que não se recomendem, locais e horários em que sua apresentação se mostre inadequada; II - estabelecer os meios legais que garantam à pessoa e à família a possibilidade de se defenderem de programas ou programações de rádio e televisão que contrariem o disposto no art. 221, bem como da propaganda de produtos, práticas e serviços que possam ser nocivos à saúde e ao meio ambiente".
} 
saúde e ao meio ambiente, enquanto, no parágrafo $4^{\text {o18 }}$, contém rol taxativo dos produtos potencialmente nocivos, isto é, cujo uso já se presume de efeitos nocivos.

É dever da família, da sociedade e do Estado a tutela da criança e do adolescente, conforme decorre no artigo 227 da Constituição ${ }^{19}$. No mesmo sentido, tem-se o artigo $4^{\text {o20 }}$ do Estatuto da Criança e do Adolescente. $\mathrm{O}$ artigo $70^{21}$ do mesmo Estatuto aborda que é dever de todos prevenir a violação ou ameaça aos direitos das crianças e adolescentes e o artigo $3^{\circ 22}$ reconhece os direitos fundamentais da criança e do adolescente.

O artigo $17^{23}$ do referido Estatuto determina a obrigatoriedade de respeito a integridade física, psíquica e moral das crianças e adolescentes. No que concerne à publicidade, o artigo $71^{24}$ do referido Estatuto cuida da proteção da criança contra o conteúdo inadequado das mensagens publicitárias. Nesse sentido, com base no citado artigo 17 e artigo 71, a publicidade direcionada as crianças que aproveita-se de sua reduzida capacidade de entendimento, ofende tais direitos.

O Código de Defesa do Consumidor, em seu artigo 37, parágrafo segundo ${ }^{25}$, declara abusiva a publicidade direcionada ao público infantil, pois essa se aproveita da deficiência de julgamento da criança. Assim, não é vedada a publicidade voltada ao público infantil, mas

${ }^{18}$ Artigo 220 da Constituição Federal de 1988: "§ $4^{\circ}$ A propaganda comercial de tabaco, bebidas alcoólicas, agrotóxicos, medicamentos e terapias estará sujeita a restrições legais, nos termos do inciso II do parágrafo anterior, e conterá, sempre que necessário, advertência sobre os malefícios decorrentes de seu uso".

19 Artigo 227 da Constituição Federal de 1988: "É dever da família, da sociedade e do Estado assegurar à criança, ao adolescente e ao jovem, com absoluta prioridade, o direito à vida, à saúde, à alimentação, à educação, ao lazer, à profissionalização, à cultura, à dignidade, ao respeito, à liberdade e à convivência familiar e comunitária, além de colocá-los a salvo de toda forma de negligência, discriminação, exploração, violência, crueldade e opressão".

${ }^{20}$ Artigo $4^{\circ}$ do Estatuto da Criança e do Adolescente: "É dever da família, da comunidade, da sociedade em geral e do poder público assegurar, com absoluta prioridade, a efetivação dos direitos referentes à vida, à saúde, à alimentação, à educação, ao esporte, ao lazer, à profissionalização, à cultura, à dignidade, ao respeito, à liberdade e à convivência familiar e comunitária".

${ }^{21}$ Artigo 70 do Estatuto da Criança e do Adolescente: "É dever de todos prevenir a ocorrência de ameaça ou violação dos direitos da criança e do adolescente".

${ }^{22}$ Artigo $3^{\circ}$ do Estatuto da Criança e do Adolescente: “A criança e o adolescente gozam de todos os direitos fundamentais inerentes à pessoa humana, sem prejuízo da proteção integral de que trata esta Lei, assegurandose-lhes, por lei ou por outros meios, todas as oportunidades e facilidades, a fim de lhes facultar o desenvolvimento físico, mental, moral, espiritual e social, em condições de liberdade e de dignidade".

${ }^{23}$ Artigo 17 do Estatuto da Criança e do Adolescente: "O direito ao respeito consiste na inviolabilidade da integridade física, psíquica e moral da criança e do adolescente, abrangendo a preservação da imagem, da identidade, da autonomia, dos valores, ideias e crenças, dos espaços e objetos pessoais".

${ }^{24}$ Artigo 71 do Estatuto da Criança e do Adolescente: "A criança e o adolescente têm direito a informação, cultura, lazer, esportes, diversões, espetáculos e produtos e serviços que respeitem sua condição peculiar de pessoa em desenvolvimento".

${ }^{25}$ Artigo 37 do Código de Defesa do Consumidor: "É proibida toda publicidade enganosa ou abusiva. [...] § $2^{\circ}$ É abusiva, dentre outras a publicidade discriminatória de qualquer natureza, a que incite à violência, explore o medo ou a superstição, se aproveite da deficiência de julgamento e experiência da criança, desrespeita valores ambientais, ou que seja capaz de induzir o consumidor a se comportar de forma prejudicial ou perigosa à sua saúde ou segurança. 
apenas e tão somente se proíbem aquelas que sejam abusivas ou enganosas, já definidas anteriormente.

Com a finalidade de definir o que é a publicidade abusiva dirigida a criança, o Conselho Nacional da Criança e do Adolescente (CONANDA) editou a Resolução número 163 que dispôs sobre a abusividade do direcionamento de publicidade e comunicação mercadológica ${ }^{26}$ a criança e ao adolescente. $\mathrm{O}$ artigo $2^{\text {o27 }}$ da respectiva Resolução determina abusiva a prática do direcionamento de publicidade e comunicação mercadológica à criança, com a intenção de persuadi-la para o consumo de qualquer produto ou serviço, apresentando uma lista não exaustiva.

Ainda, existe uma série de entidades, documentos e afins que buscam a proteção da criança, no que se refere a publicidade. Indispensável mencionar o Instituto Alana, organização sem fins lucrativos, que atua fortemente na missão de cuidado com a criança. Tal Instituto consta com programas próprios e com parceiros, dentre eles destaca-se o programa "Criança e Consumo" que atua com objetivo de conscientização do impacto que a publicidade tem sobre o público infantil.

A Convenção da Organização das Nações Unidas (ONU) sobre os Direitos das Crianças, ratificado por 196 países, visa a proteção das crianças em todo o mundo. Possui como um de seus princípios o interesse superior da criança. Também, o Plano Decenal dos Direitos Humanos de Crianças e Adolescentes dispõe de um conjunto de diretrizes que visa nortear a execução de políticas públicas para proteção e defesa dos direitos da criança e do adolescente.

\footnotetext{
26 A comunicação mercadológica tem um conceito mais amplo do que a publicidade. No conceito de comunicação mercadológica "não está incluída só a publicidade comercial, mas toda prática ou atividade que tenha por finalidade divulgar produtos, serviços, marcas, empresas ou um estilo de vida" (d'AQUINO, 2016, p. 5). No artigo $1^{\circ}$ da Resolução número 163 do Conselho Nacional da Criança e do Adolescente (CONANDA), está descrito o que se entende por comunicação mercadológica: “[...] $\S 1^{\circ}$ Por 'comunicação mercadológica' entende-se toda e qualquer atividade de comunicação comercial, inclusive publicidade, para a divulgação de produtos, serviços, marcas e empresas independentemente do suporte, da mídia ou do meio utilizado. $\S 2^{\circ} \mathrm{A}$ comunicação mercadológica abrange, dentre outras ferramentas, anúncios impressos, comerciais televisivos, spots de rádio, banners e páginas na internet, embalagens, promoções, merchandising, ações por meio de shows e apresentações e disposição dos produtos nos pontos de vendas".

27 Artigo $2^{\circ}$ da Resolução número 163 do Conselho Nacional da Criança e do Adolescente (CONANDA): "Considera-se abusiva, em razão da política nacional de atendimento da criança e do adolescente, a prática do direcionamento de publicidade e de comunicação mercadológica à criança, com a intenção de persuadi-la para o consumo de qualquer produto ou serviço e utilizando-se, dentre outros, dos seguintes aspectos: I - linguagem infantil, efeitos especiais e excesso de cores; II - trilhas sonoras de músicas infantis ou cantadas por vozes de criança; III - representação de criança; IV - pessoas ou celebridades com apelo ao público infantil; V personagens ou apresentadores infantis; VI - desenho animado ou de animação; VII - bonecos ou similares; VIII - promoção com distribuição de prêmios ou de brindes colecionáveis ou com apelos ao público infantil; e IX - promoção com competições ou jogos com apelo ao público infantil [...]”.
} 
$\mathrm{O}$ artigo $5^{\mathrm{o} 28}$ da Lei número 13.257 de março de 2016 dispõe sobre as políticas públicas para a primeira infância. Aborda que constitui área prioritária para as políticas públicas não só a proteção contra a publicidade, mas a proteção contra a pressão consumista e a adoção de medidas que evitem a exposição precoce a comunicação mercadológica.

Cumpre destacar que, em 2001 foi apresentado o Projeto de Lei Número 5.921, que visava acrescentar o $\S 2^{\circ} \mathrm{A}$. no artigo 37 do Código de Defesa do Consumidor, com a justificativa de avaliar a relação da criança com a publicidade. O parágrafo possuía a seguinte redação: "É também proibida a publicidade destinada a promover a venda de produtos infantis, assim considerados aqueles destinados apenas à criança”, porém o mesmo foi arquivado, sem aprovação, no ano de 2019.

Dessa forma, justifica-se a relevância e atualidade da pesquisa, tendo em vista o grande impacto no desenvolvimento da criança causado pela publicidade infantil. Também, face ao consumo exagerado de produtos não necessários para nossa sobrevivência, mas que acabam trazendo uma ideia de felicidade e com isso impulsionando a compra de coisas que não precisamos, de consumir mais do que necessitamos e, consequentemente, descartar, o que tem impacto direto no meio ambiente, desconsiderando o uso moderado dos bens naturais.

\section{CONSIDERAÇÕES FINAIS}

A sociedade de consumo tem como principal característica o incentivo ao ato de consumir em massa. Nesse contexto surgiu o consumismo, prática pela qual os indivíduos são incentivados a consumir além do necessário para a sua sobrevivência. Tal conduta configurase pelas constantes mudanças das necessidades e desejos do consumidor, os quais precisam ser satisfeitos através da aquisição de novos produtos.

A fim de incentivar o consumo em massa e com o intuito de criar desejos, surge a publicidade. Utilizando-se de diversos meios de comunicação, a publicidade consegue aproximar consumidores e fornecedores. Seu principal papel é fazer com que os níveis de vendas se mantenham elevados, ou seja, incentiva o consumo.

\footnotetext{
${ }^{28}$ Artigo $5^{\circ}$ da Lei Número 13.257 de março de 2016: “Constituem áreas prioritárias para as políticas públicas para a primeira infância a saúde, a alimentação e a nutrição, a educação infantil, a convivência familiar e comunitária, a assistência social à família da criança, a cultura, o brincar e o lazer, o espaço e o meio ambiente, bem como a proteção contra toda forma de violência e de pressão consumista, a prevenção de acidentes e a adoção de medidas que evitem a exposição precoce à comunicação mercadológica".
} 
$\mathrm{Na}$ maioria das vezes, as pessoas não percebem que não precisam de determinados produtos, que eles não são essenciais, mas consomem pelo simples fato de satisfazer esses desejos. O comprar e o descartar é o que movimenta a economia e, se a população deixar de comprar, o impacto na economia será grave, provocando um desaquecimento econômico sem precedentes em todos os setores, ocasionando milhares de desempregados.

É dever, não só do Estado, proteger e regular as relações de consumo, visando o combate as práticas e publicidades abusivas e enganosas, que estimulam o consumo exagerado. Dentre os consumidores, alguns desses são considerados hipervulneráveis, como é o caso das crianças, pois possuem sua vulnerabilidade potencializada.

A mídia tem impacto sobre os consumidores e de forma mais intensa em relação as crianças, despertando o desejo de consumo e a ilusão de felicidade. A legislação existente é suficiente, porém é necessário reforçar a fiscalização da prática de publicidade enganosa e abusiva destinada ao público infantil e dessa forma frear e punir os abusos.

Também é necessário implantar nas escolas a educação para o consumo, conforme previsão do Código de Defesa do Consumidor, a inclusão pode ser feita de forma transversal passando pelas diversas fases e disciplinas da educação, desde a escola infantil, ensino fundamental, médio e nos cursos de graduação das universidades. Além de ser uma questão de cidadania, consumir conscientemente é pensar nas futuras gerações e na preservação do meio ambiente.

\section{REFERÊNCIAS}

BAUDRILLARD, Jean. A sociedade de consumo. Tradução de Artur Morão. Rio de Janeiro: Elfos Ed., 1995.

BAUMAN, Zygmunt. Vidas para consumo: a transformação das pessoas em mercadorias. Tradução de Carlos Alberto Medeiros. Rio de Janeiro: Jorge Zahar Ed., 2008.

BOLKENHAGEN, Lina. Merchandising como técnica de publicidade o seu impacto no mercado de consumo e efeitos jurídicos de sua veiculação. Revista dos Tribunais, São Paulo, vol. 80/2011, p. 337 - 403, out - dez de 2011.

BRASIL. Código Brasileiro De Autorregulamentação Publicitária. São Paulo, 1980. Disponível em: http://secom.gov.br/orientacoes-gerais/publicidade/codigo-bras-deautorregulamentacao.pdf. Acesso em: 06 set. 2020.

CONANDA - Conselho Nacional dos Direitos da Criança e do Adolescente.

Disponível em: <http://www.crianca.mppr.mp.br/pagina-1562.html>. Acesso em 08 set. 2020. 
Conselho Nacional de Autorregulamentação Publicitária - CONAR. Disponível em: < http://www.conar.org.br/>. Acesso em 07 set. 2020.

Constituição (1988). Constituição da República Federativa do Brasil de 1988.

Disponível em:

<http://www.planalto.gov.br/ccivil_03/Constituicao/ConstituicaoCompilado.htm>. Acesso em: 03 set. 2020.

. Declaração dos Direitos da Criança. Disponível em: < https://www2.camara.leg.br/atividade-legislativa/comissoes/comissoes permanentes/cdhm/comite-brasileiro-de-direitos-humanos-e-politica externa/DeclDirCrian.html>. Acesso em: 02 set. 2020.

Dispõe sobre o Estatuto da Criança e do Adolescente e dá outras providências. Disponível em: <http://www.planalto.gov.br/ccivil_03/Leis/L8069.htm>. Acesso em 01 set. 2020.

Lei Federal número 8.078, de 11 de setembro de 1990. Dispõe sobre a proteção do consumidor e dá outras providências. Brasília, DF: Senado, 1990. Disponível em: http://www.planalto.gov.br/ccivil_03/LEIS/L8078.htm. Acesso em: 02 set. 2020.

Lei número 13.257, de 8 de março de 2016. Disponível em:

<http://www.planalto.gov.br/ccivil_03/_ato2015-

2018/2016/lei/113257.htm\#: :text=Disp\%C3\%B5e\%20sobre\%20as\%20pol\%C3\%ADticas\%2 0p\%C3\%BAblicas,de\%201\%C2\%BA\%20de\%20maio\%20de>. Acesso em: 06 set. 2020.

Plano Decenal dos Direitos Humanos de Crianças e Adolescentes. Disponível em: <http://www.crianca.mppr.mp.br/arquivos/File/download/plano_decenal_conanda.pdf.>Acess o em 01 set. 2020.

Projeto de Lei Número 5.921 de 12 de dezembro de 2001. Disponível em: <https://www.camara.leg.br/proposicoesWeb/fichadetramitacao?idProposicao=43201>. Acesso em 05 set. 2020.

Promulga a Convenção sobre os Direitos da Criança. Disponível em: <http://www.planalto.gov.br/ccivil_03/decreto/1990-1994/D99710.htm>. Acesso em 03 set. 2020 .

Resolução CONANDA No 163 DE 13/03/2014. Disponível em:

<https://www.legisweb.com.br/legislacao/?id=268725>. Acesso em 05 set. 2020.

Superior Tribunal de Justiça. Recurso Especial no 1.558.086 - SP. Voto da Ministra Assusete Magalhães. Disponível em: <http://www.stj.jus.br/sites/portalp/Inicio>. Acesso em: 05 set. 2020.

Superior Tribunal de Justiça. Recurso Especial no 586.316 - MG. Relator Ministro Herman Benjamin. Disponível em: 
<http://www.stj.jus.br/sites/portalp/Inicio>. Acesso em: 04 set. 2020.

BRITO, Dante Ponte de; COSTA, Pedrita Dias. Consumo pós-moderno, redes sociais e superendividamento. Revista de Direito do Consumidor, v. 130/2020, 2020, p. 79-97, jul./ago. 2020.

BURROWES, Patrícia. Viagem ao território da publicidade. In: Comunicação, mídia e consumo, vol. 2, n. 5. São Paulo. Anais eletrônicos. São Paulo: revistacmc, 2005. p. 205219.

CALGARO, Cleide; PEREIRA Agostinho Oli Koppe. A sociedade consumocentrista e seus reflexos socioambientais: a cooperação social e a democracia participativa para a preservação ambiental. Revista de Direito, Economia e Desenvolvimento Sustentável, Curitiba, v. 2, 2016, n. 2, p. 72-88, jul./dez. 2016.

CAVALIERI FILHO, Sergio. Programa de Direito do Consumidor. 5. ed. São Paulo: Atlas, 2019.

CHAISE, Valéria Falcão. A publicidade em face do Código de Defesa do Consumidor. São Paulo: Saraiva, 2001.

D’AQUINO, Lúcia Souza. A publicidade abusiva dirigida ao público infantil. Revista de Direito do Consumidor, v. 106/2016, 2016, p. 89 - 131, Jul./Ago 2016.

DAHINTEN, Augusto Franke; DAHINTEN, Bernardo Franke. A proteção do consumidor enquanto direito fundamental e direito humano: consolidação da noção de mínimo existencial de consumo. Revista de Direito do Consumidor, v. 106/2016, 2016, p. 135-165, jul./ago. 2016.

FERNANDES, Izabella Bueno; BORGES, Fábio Roberto Ferreira; VEIGA, Ricardo Teixeira; GONÇALVES, Carlos Alberto; BORGES, Admir Roberto. In-game advertising e advergame: fatores que afetam o impacto da mensagem nas ferramentas de advergaming. In: Cadernos de comunicação, Santa Maria, v. 18, n. 2, p. 89 - 109, jul-dez 2014.

FRADERA, Vera Maria Jacob. A interpretação da proibição de publicidade enganosa ou abusiva à luz do princípio da boa-fé: o dever de informar no Código de Defesa do Consumidor. Revista dos Tribunais, São Paulo, vol. 4/1992, p. 173-191, out-dez. 1992.

GOMES, Neusa Demartini; CASTRO, Maria Lília Dias de. Publicidade: um olhar metodológico. In: PEREZ, Clotilde; BARBOZA, Ivan Santo. Hiperpublicidade: fundamentos e interfaces. São Paulo: Cengage Learning, 2007.

GONÇALES, Márcio Carbaça. Publicidade e propaganda. Curitiba: IESDE Brasil S. A., 2009.

GRINOVER, Ada Pellegrini, et al. Código Brasileiro de Defesa do Consumidor: comentado pelos autores do anteprojeto: direito material e processo coletivo: volume único. 12. ed. Rio de Janeiro: Forense, 2019. 
INSTITO ALANA. Disponível em: <https://alana.org.br/>. Acesso em 08 set. 2020.

LIPOVETSKY, Gilles. A felicidade paradoxal: ensaio sobre a sociedade de hiperconsumo. Tradução de Maria Lucia Machado. São Paulo: Companhia das Letras, 2007.

. Sedução, publicidade e pós-modernidade. Revista FAMECOS, Porto Alegre, 2000, n.12, jun. 2000 .

LOPES, Maria Elizabete Vilaça. O consumidor e a publicidade. Revista dos Tribunais, São Paulo, vol. 4, p. 949 - 982, out 2011.

MIRAGEM, Bruno. Curso de Direito do Consumidor. 4. ed. rev., atual. e ampl. São Paulo: Editora Revista dos Tribunais, 2013.

MORAES, Paulo Valério Dal Pai. Código de Defesa do Consumidor: o princípio da vulnerabilidade no contrato, na publicidade, nas demais práticas comerciais: interpretação sistemática do direito. 3. Ed. - Porto Alegre Livraria do Advogado, 2009.

NERY JR. Nelson. Limites para a publicidade infantil - direito fundamental à comunicação e liberdade de expressão da iniciativa privada. Soluções Práticas de Direito, v.1/2014, 2014, p. 427-465, set. 2014.

PEREIRA, Agostinho Oli Koppe; CALGARO, Cleide; PEREIRA, Henrique Mioranza Koppe. Consumocentrismo e os seus reflexos socioambientais na sociedade contemporânea. Revista Direito Ambiental e sociedade, v. 6, 2016, n. 2. p. 264-279, 2016.

SATO, Silvio Koiti. Abrindo a embalagem na rede: reflexões sobre consumo e cultura digital a partir dos unboxing videos. In: Congresso Internacional em Comunicação e Consumo, 2016, São Paulo. Anais eletrônicos. São Paulo: COMUNICON, 2016.

SCHMITT, Cristiano Heineck. Consumidores Hipervulneráveis - A proteção do idoso no mercado de consumo. São Paulo: Atlas, 2014.

SANTOS, Milton. Por uma outra globalização: do pensamento único à consciência universal. 25.ed. Rio de Janeiro: 2015.

SILVA, Ana Beatriz Barbosa. Mentes consumistas: do consumismo à compulsão por compras. São Paulo: Globo, 2014.

TEIXEIRA, Rodrigo Valente Giublin. Unboxing: os vídeos publicitários camuflados e a hipervulnerabilidade dos consumidores infantis. Revista Direitos Sociais e Políticas Públicas (UNIFAFIBE), São Paulo, v. 6, n. 1, p. 454-492, 2018.

VELHO, Adriana Galli. Marketing público. Porto Alegre: SAGAH, 2018. 